удК 316.477

В. П. Агафонова

Байкальский государственный университет, г. Иркутск, Российккая Федерация

\title{
ПОДХОДЫ К ПОНИМАНИЮ КАРЬЕРЫ, ЕЕ СУЩНОСТЬ И ОСОБЕННОСТИ
}

\begin{abstract}
АНнотАция. В статье описываются мнения различных авторов по толкованию термина «карьера», дается обзор определений рассматриваемого понятия, а также раскрываются его сущностные характеристики, так как анализ научных работ, посвященных указанной проблеме, свидетельствует о многочисленности суждений о карьере и ее аспектах. Одновременно осуществляется синтезирование имеющейся информации по заданной теме и предлагается разработанное на основе анализа разных формулировок понятия «карьера» собственное определение указанного термина. При этом выделяются два основных подхода, на которые целенаправленно сделан упор в представленном исследовании, поэтому они освящены более подробно. Более того, проводится разграничение понятий «карьера» и «профессиональная карьера», сформулировано и представлено свое толкование данных терминов.

кЛючЕВЫЕ СлОВА. Карьера; профессиональная карьера; карьерный рост; развитие карьеры; подходы к пониманию карьеры; особенности профессиональной карьеры. ИНФОРМАЦИЯ О СТАТЬЕ. Дата поступления 11 марта 2016 г.; дата принятия к печати 30 марта 2016 г.; дата онлайн-размещения 31 мая 2016 г.
\end{abstract}

V. P. Agafonova

Baikal State University,

Irkutsk, Russian Federation

\section{APPROACHES TO UNDERSTANDING CAREER, ITS ESSENCE AND FEATURES}

\begin{abstract}
The article describes opinions of various authors on interpretation of the term «career», gives a review of definitions of this concept, as well reveals its intrinsic characteristics, as an analysis of the scientific works devoted to this specific problem testifies a large number of judgments referring career and its aspects. Simultaneously, it synthesizes the available information on the given topic and offers its own definition of the said term developed on the basis of analyzing various wordings of the concept "career». In this context, the article specifies two main approaches that are purposefully made a focus on in the presented research, so they are highlighted in more detail. Moreover, it makes a distinction between the concepts "career» and "professional career», formulates and presents its interpretation of these terms.

KEYWORDS. Career; professional career; career growth; career development; approaches to understanding career; features of professional career.

ARTICLE INFO. Received March 14, 2016; accepted March 30, 2016; available online May $31,2016$.
\end{abstract}

Карьера, в целом, и, профессиональная, в частности - это довольно сложный предмет для научного изучения, который исследуется представителями различных дисциплин, таких как социология, психология, экономика и т. д. Исходя из этого, можно отметить, что понятие карьеры является междисциплинарным и сформировалось на основе синтеза различных теоретических подходов.

В многочисленных научных трудах рассматривались различные стороны понятия «карьера». Для исследования нами был проведен анализ более 60 научных работ, посвященных данной теме и опубликованных за последнее десятилетие

(C) В. П.Агафонова, 2016

\section{Baikal Research Journal}

электронный научный журнал Байкальского государственного университета 
(см., напр.: [1-11]). Обзор указанной литературы позволил сделать вывод, что более всего внимание уделялось проблеме восприятия и планирования карьеры учениками школ и студентами вузов - $45 \%$; на втором месте - вопросы карьеры государственных служащих - $23 \%$; на третьем - психологические аспекты карьеры $21 \%$; на четвертом - построение карьеры в системе менеджмента - $11 \%$.

Считаем необходимым обратить внимание на подходы ученых к пониманию как карьеры, так и карьеры профессиональной. Так, словарь русского языка С. И. Ожегова дает толкование карьеры в двух значениях. Первое из них указывается с пометкой «устар.» (устаревшее) и определяет карьеру как род занятий, профессию. Второе путь к успехам, видному положению в обществе, на служебном поприще, а также достижение такого положения [12]. Такое определение имеет слишком общий характер и не рассматривает основных сущностных характеристик данного термина.

Так, кандидат социологических наук Д. А. Ткач отмечает, что карьера - это уровень социально-экономического поведения в человеческом обществе, включающий в себя индивидуальные карьерные устремления личности [13, с. 11]. С данным определением можно согласиться, но, на наш взгляд, необходимо определить, какими карьерными устремлениями при этом обладает личность. Поскольку такие устремления являются факторами развития карьеры, это позволит шире раскрыть ее сущность, и, соответственно, предложенное определение станет более полным.

Кандидат юридических наук О. Г. Лукашова дает достаточно обширное определение карьеры, рассматривая ее, как продвижение индивида по ступеням профессиональной лестницы в течение всей трудовой жизни, смену видов работ на пути к достижению успеха на служебном поприще, выражающемся в занятии более престижными видами труда, более высокой оплате труда, большей служебной ответственности и власти. Наряду с понятием «профессиональная карьера» она также рассматривает термин «трудовая карьера», отмечая, что последняя может быть осуществлена работником как на разных предприятиях, так и в рамках одной организации [14].

Е. В. Пахомова пишет, что карьера - это процесс профессионального формирования субъекта, обогащение опытом, достижение социального признания [15, с. 113]. Предложенное определение, на наш взгляд, не раскрывает всей сущности понятия. Во-первых, не ясно, что подразумевается под профессиональным формированием субъекта, во-вторых, не только социальное признание является двигателем карьеры, но и такие факторы, как власть, успех, материальное вознаграждение и др.

Н. В. Буравцова определяет карьеру в широком смысле, как общую последовательность этапов развития человека в основных сферах жизни [16, с. 39]. При этом не определяя данное понятие в узком смысле, да и вообще, такое определение охватывает слишком широкий круг действия.

Таким образом, мы видим, что определений карьеры достаточно много в научной литературе, и авторы вкладывают разное содержание и смысл в этот термин. Анализ понятий позволяет утверждать, что, во-первых, большинство авторов рассматривают понятие карьера как определенный процесс, во-вторых, многие из них недостаточно раскрывают всю сущность данного понятия, отражая лишь некоторые аспекты его содержания. Стоит учитывать, что законодательством понятие карьеры не регламентировано, однако, в частности, порядок прохождения государственной и муниципальной службы (построение карьеры в органах публичной власти) достаточно детально закреплен, причем служащий связан с законодательством большим числом запретов и ограничений, «соблюдение которых становится предметом государственного контроля» $[17$, с. 52$]$.

Таким образом, можно выделить четыре основных подхода к изучению карьеры:

1. Экономический подход - последовательность позиций, занимаемых личностью в имущественной иерархии, которая измеряется уровнем дохода, прино-

\section{Baikal Research Journal}


симым профессиональной деятельностью $[18$, с. 16]. Мотивацией здесь является власть, получаемая при достижении положительных результатов в карьерном продвижении, а также получение большего дохода и материальной обеспеченности. Поскольку, как отмечают некоторые авторы, «последнее десятилетие характеризуется особенно резким увеличением численности бедного населения" $[19$, c. 80], очевидно, что главным двигателем карьерного роста является стремление к материальной выгоде. При этом в коллективе, где сотрудники обладают разным уровнем достатка, образуется так называемая «гонка за лидером», что, несомненно, увеличивает мотивационные условия для развития карьеры, а повышение его конкурентоспособности означает улучшение материального положения, общего психологического состояния [20, с. 74].

2. Психологический подход - здесь карьера воспринимается и рассматривается через призму самой сути психологической науки, т. е. в изучении профессиональной карьеры или карьерного роста на первом плане всегда стоит переживание индивидом собственного карьерного пути, осмысление профессионального, трудового опыта, личностное понимание своих возможностей, способностей и т. д. В таком контексте развитие карьеры зависит от влияния внешних факторов на внутреннее восприятие собственного «Я» в трудовой системе, а также от того, какое место и роль для себя определяет индивид в структуре того или иного органа, организации, хотя немаловажно и влияние внутренней ситуации в коллективе на поведение сотрудника.

3. Педагогический подход - карьера понимается как целенаправленный процесс и результат формирования жизненной траектории человека, охватывающий ближнюю и дальнюю перспективу с учетом ценностей и целей общества и личности, позволяющий осуществлять рефлексивное видение себя и своего места в системе общественных и производственных отношений $[16$, с. 20]. Такой подход рассматривает, каким образом образовательные учреждения и институты влияют и воздействуют на возникновение и развитие у индивида определенной установки, ориентированной на благополучный карьерный прогресс.

4. Социологический подход - представляет карьеру как часть процесса социально-профессиональной мобильности и осмысливается как продвижение наиболее способных индивидов по ступеням профессиональной, социальной, производственной или иной иерархии. Профессиональная карьера определяется объективными и субъективными обстоятельствами жизнедеятельности социума. Представители данного подхода рассматривают карьеру в широком и узком смысле. Так, в широком смысле карьера понимается как общая последовательность этапов развития человека в основных сферах жизни (семейной, трудовой, досуговой). В узком смысле - как динамика положения и активности личности в трудовой деятельности $[13$, с. 11]. Такой подход в качестве субъекта карьеры рассматривает индивида, взаимодействующего с социумом. Безусловно, каждый такой индивид обладает определенным набором социальных потребностей, которые ему необходимо удовлетворить в зависимости от уровня его аффилиации. Главной потребностью, пожалуй, является социальное признание личности, которое достигается путем приобретения определенного статуса в карьере и, соответственно, необходимого уровня доходов.

Каждый из рассмотренных подходов, так или иначе, является аддендой (дополнением) другого, проанализируем некоторые из них. Например, очевидна тесная связь социологического и экономического подходов, поскольку социальная сфера представляет весьма существенную часть современной экономики, а затраты государства на реализацию политики в этой сфере и расходы населения на приобретение производимых в ней благ составляют от 30 до 45 \% ВВП [21, с. 46]. Разумеется, что в зависимости от развития экономики повышается уровень качества жизни населения, соответственно, изменяется уровень мотивации карьерного роста. В научной

\section{Baikal Research Journal}


литературе также часто можно встретить мнение о том, что социологический и психологический подходы к пониманию карьеры очень схожи [22], но, на наш взгляд, данное утверждение не совсем верно, поскольку социологический контекст не предполагает изучение собственного восприятия индивида, а исследует его положение и роль в социуме в соответствии с занимаемой им должностью.

Полагаем, что карьеру необходимо рассматривать, прежде всего, с точки зрения социальной и профессиональной. Эти контексты по-разному раскрывают и понимают термин «карьера», определяют каждый свои задачи для достижения определенного результата, да и сам конечный результат, безусловно, различен. В нашем представлении карьера с профессиональной точки зрения - процесс приобретения опыта, реализации личностного потенциала, развития и роста профессиональных навыков отдельного индивида, а с социологической точки зрения - карьера есть деятельность индивида, направленная на достижение успеха в социуме, т. е. приобретение социального признания и уважения, а также обладание определенным положением и ролью индивида в обществе.

Разница между данными подходами очевидна. Поскольку главной задачей карьеры с профессиональной точки зрения является накопление профессионального опыта и развитие профессионализма, то достигнув успехов в карьере, в этом случае, индивид утверждает себя как хорошего работника и специалиста в той или иной профессиональной деятельности. С точки зрения социологического контекста (подхода) - главной задачей человека становится утверждение себя в обществе как индивида, вследствие этого результатом является достижение признания и утверждение себя как уважаемого человека, достигшего успеха.

На основании указанного, карьера - это деятельность отдельного индивида, направленная на получение, развитие и реализацию опыта и профессиональных навыков с целью получения определенного положения в обществе, социального признания и уважения, достигаемого путем приобретения власти, высокого уровня дохода и материальной обеспеченности. В связи с чем для понимания построения карьеры отдельного индивида мы разработали несколько путей развития профессиональной карьеры, которые выглядят следующим образом:

1. Горизонтальная карьера (модель $A$ ) - это профессиональный рост, направленный на приобретение опыта и профессиональных навыков и достижение наивысшего уровня мастерства. Это скорее процесс реализации себя в условиях профессиональной деятельности. Данный путь развития карьеры представляет собой такую ситуацию, при которой индивид стремится, в основном, к достижению знаний и приобретению максимального опыта. Однако при получении максимального опыта индивид не достигает максимальной должности и останавливается лишь на начальных стадиях, не переходя, например, в начальствующий состав организации.

2. Вертикальная карьера (модель $B$ ) - это профессиональный рост, направленный на достижение или получение определенной должности, звания. Навыки и опыт здесь отходят на второй план. Индивид движется вверх, к своей цели, при этом достигая максимальной должности, он не достигает максимального опыта и профессиональных знаний.

3. Диагональная карьера (модель $C$ ) - это оптимальная совокупность горизонтальной и вертикальной карьеры, идеальное сочетание целей при осуществлении профессиональной деятельности, олицетворение идеальной модели продвижения сотрудника по карьерной лестнице. Если по моделям развития $A$ и $B$ индивид движется одновременно и примерно одинаково, то, соответственно, при достижении максимальной должности он должен и будет обладать максимальным опытом, необходимым для соответствующего звания или поста.

\section{Baikal Research Journal}


Такая схема карьерного развития показывает важность выбора индивида, как именно и по какой модели продвигаться. Понятно, что чем ближе к диагональной траектории будет двигаться сотрудник, тем успешнее будет его карьера.

Изучая данный вопрос, стоит обратить внимание на немаловажный факт того, что, проходя карьерный путь, нужно попасть в определенные временные рамки достигнутая должность в идеальном представлении должна соответствовать определенному возрасту сотрудника, поскольку опыт и знания требуют времени, так как чаще всего молодой сотрудник в силу своего возраста не может владеть и понимать ту или иную информацию, которая необходима для осуществления профессиональной деятельности в соответствии с занимаемой должностью.

Подводя итоги исследования, следует отметить, что термин «карьера» изучается с точки зрения самых различных подходов многими авторами. Выделив несколько основных, можно было увидеть насколько многогранно это понятие, поскольку каждый из таких подходов раскрывает свою грань данного термина. Определив несколько моделей развития карьеры, можно говорить о том, что профессиональный рост, который также включает в себя и экономический, и социальный рост, целиком зависит от субъективного фактора. Вне зависимости от того, с какой точки зрения рассматривать данный феномен, развитие карьеры может прогрессировать исключительно в том случае, если у индивида присутствует мотивация, которая может быть вызвана (теперь уже в зависимости от подхода) разнообразными факторами, такими как статус в обществе, признание социума, материальное обеспечение и др.

\section{Список использованной литературы}

1. Громова Е. М. Построение профессиональной карьеры современными студентами: гендерный аспект [Электронный ресурс] / Е. М. Громова, Д. И. Беркутова, Т. А. Горшкова // Современные проблемы науки и образования. - 2013. - № 5. - Режим доступа : http://www. science-education.ru/ru/article/view?id=10456.

2. Дахно Е. В. Управление развитием карьеры государственных служащих в России / Е. В. Дахно // Историческая и социально-образовательная мысль. - 2012. - № 2. - С. 118-120.

3. Жданова С. Ю. Особенности представлений студентов о карьере / С. Ю. Жданова // Вектор науки Тольяттинского государственного университета. - 2011. - № 4. - C. 102-105.

4. Зайцев Г. Г. Управление карьерой менеджера: сущность, актуальность, проблемы исследования / Г. Г. Зайцев // Вестник Ленинградского государственного университета имени А. С. Пушкина. - 2011. - № 3. - С. 98-106.

5. Лазукова Е. А. Наем и карьера государственных служащих / Е. А. Лазукова // Власть. - 2013. - № 5. - С. 181-185.

6. Молчанова А. В. Индивидуальная стратегия профессиональной карьеры специалиста социально-педагогического профиля / А. В. Молчанова // Проблемы и перспективы развития образования в России. - 2015. - № 32. - С. 166-172.

7. Морева М. Н. К вопросу о понятии «Карьеры» в системе государственной службы / М. Н. Морева // Бизнес в законе. - 2008. - № 3. - С. 131-132.

8. Саховский И. А. Мотивационные детерминанты процесса планирования карьеры обучающихся на этапе профильного обучения общеобразовательных школ / И. А. Саховский // Сибирский педагогический журнал. - 2010. - № 6. - С. 359-366.

9. Сотникова С. И. Управление карьерой персонала в системе менеджмента современной организации / С. И. Сотникова // Вестник Омского государственного университета. Сер.: Экономика. - 2014. - № 3. - С. 60-67.

10. Устинова О. В. Управление карьерой менеджера в современной организации / О. В. Устинова, И. В. Пивоварова / / Современные проблемы науки и образования. - 2015. № 1-1. - C. 14-46.

11. Хисматуллин А. Р. Психологический аспект планирования карьеры / А. Р. Хисматуллин // СМАЛЬТА. - 2015. - № 5. - С. 181-185.

12. Ожегов С. И. Толковый словарь русского языка / С. И. Ожегов ; М. Ю. Шведова. М. : Рус. яз., 1992. -797 c.

\section{Baikal Research Journal}


13. Ткач Д. А. Профессиональная карьера современной молодежи : дис. ... канд. социол. наук : 22.00.03 / Д. А. Ткач. - Саратов, 2004. - 152 с.

14. Лукашова О. Г. Трудовая карьера [Электронный ресурс] / О. Г. Лушакова. - Режим доступа: http://voluntary.ru/dictionary/568/word/trudovaja-karera.

15. Пахомова Е. В. Понятие «карьера»: анализ определений / Е. В. Пахомова // Вестник Южно-Уральского государственного университета. Сер.: Психология. - 2013. — Т. 6, № 2. - C. 111-115.

16. Буравцова Н. В. Современные подходы к карьере и карьеризму / Н. В. Буравцова // СМАЛЬТА. - 2014. - № 1. - С. 39-42.

17. Якимова Е. М. Совершенствование системы государственного контроля в Российской Федерации / Е. М. Якимова // Вестник Евразийской Академии административных наук. 2013. - № 1. - С. 51-57.

18. Ковалева Л. Ю. Педагогические условия личностного и профессионального самоопределения старшеклассников в процессе планирования карьеры : автореф. дис. ... канд. пед. наук : 13.00.01 / Л. Ю. Ковалева. - Томск, 2000. - 18 с.

19. Токарский Б. Л. Социологическое исследование экономической мотивации населения / Б. Л. Токарский, Н. М. Токарская // Известия Иркутской геосударственной экономической академии. - 2005. - № 1 (42). - С. 75-81.

20. Коломейцв Ю. А. Основные научные подходы к профессиональной карьере и карьерным ориентациям личности / Ю. А. Коломейцев, А. А. Ж данович // Проблемы управления. - 2008. - № 1 (26). - С. 207-215.

21. Озерникова Т. Г. Мотивация и конкурентоспособность работников : проблема взаимосвязи / Т. Г. Озерникова // Известия Иркутской государственной экономической академии. - 2005. - № 1 (42). - С. 71-75.

22. Самаруха В. И. Роль социальной сферы в повышении качества жизни населения / В. И. Самаруха, А. В. Гуляева // Известия Иркутской государственной экономической академии. - 2011. — № 4 (78). - С. 46-50.

\section{References}

1. Gromova E. M., Berkutova D. I., Gorshkova T. A. Modern students' professional career planning: a gender aspect. Sovremennye problemy nauki i obrazovaniya = Recent Developments in Science and Education, 2013, no. 5. Available at: http://www.science-education.ru/ru/article/ view?id=10456. (In Russian).

2. Dakhno E. V. Career management of civil servants in Russia. Istoricheskaya i sotsial'no-obrazovatel'naya mysl' = Historical and Social Educational Ideas, 2012, no. 2, pp. 118-120. (In Russian).

3. Zhdanova S. Yu. Features of students' views about career. Vektor nauki Tol'yattinskogo gosudarstvennogo universiteta $=$ Science Vector of Togliatti State University, 2011, no. 4, pp. 102-105. (In Russian).

4. Zaitsev G. G. Managing manager's career: essence, topicality, problems of research. Leningradskogo gosudarstvennogo universiteta imeni A. S. Pushkina = Bulletin of Pushkin Leningrad State University, 2011, no. 3, pp. 98-106. (In Russian).

5. Lazukova E. A. Employment and career of government workers. Vlast' = The Power, 2013, no. 5, pp. 181-185. (In Russian).

6. Molchanova A. V. Individual strategy of professional career for a specialist in socio-pedagogical area. Problemy $i$ perspektivy razvitiya obrazovaniya $v$ Rossii $=$ Issues and Development Trends of Education in Russia, 2015, no. 32, pp. 166-172. (In Russian).

7. Moreva M. N. On issue of the concept «Careers» in the public service system. Biznes $v z a$ kone $=$ Business in Law, 2008, no. 3, pp. 131-132. (In Russian).

8. Sakhovsky I. A. Motivational determinants of the career planning process of students at the stage of specialist education in comprehensive schools. Sibirskii pedagogicheskii zhurnal = Siberian Pedagogical Journal, 2010, no. 6, pp. 359-366. (In Russian).

9. Sotnikova S. I. Career management in management of modern organizations. Vestnik Omskogo gosudarstvennogo universiteta. Seriya: Ekonomika = Bulletin of Omsk University. Economics Series, 2014, no. 3, pp. 60-67. (In Russian).

10. Ustinova O. V., Pivovarova I. V. Career management manager in the modern organization. Sovremennye problemy nauki i obrazovaniya = Recent Developments in Science and Education, 2015, no. 1-1, pp. 14-49. (In Russian).

\section{Baikal Research Journal}


11. Khismatullin A. R. Psychological aspect of career planning. SMALTA, 2015, no. 5, pp. 181-185. (In Russian).

12. Ozhegov S. I., Shvedova M. Yu. (ed.) Slovar russkogo yazyka [Dictionary of the Russian language]. Moscow, Russkiy yazyk Publ., 1992. 797 p.

13. Tkach D. A. Professional'naya kar'era sovremennoi molodezhi. Kand. Diss. [Professional career of modern youth. Cand. Diss.]. Saratov, 2004. 152 p.

14. Lukashova O. G. Trudovaya kar'era [Working career]. Available at: http://voluntary.ru/ dictionary/568/word/trudovaja-karera. (In Russian).

15. Pakhomova E. V. The concept of "career»: analysis of terms. Vestnik Yuzhno-Ural'skogo gosudarstvennogo universiteta. Seriya: Psikhologiya = Bulletin of South Urals State University. Psychology Series, 2013, vol. 6, no. 2, pp. 111-115. (In Russian).

16. Buravtsova N. V. Modern approaches to career and careerism. SMALTA, 2014, no. 1, pp. 39-42. (In Russian).

17. Yakimova E. M. Improving State Control System in the Russian Federation. Vestnik Evraziiskoi Akademii administrativnykh nauk = Bulletin of Eurasian Academy of Administrative Sciences, 2013, no. 1, pp. 51-57. (In Russian).

18. Kovaleva L. Yu. Pedagogicheskie usloviya lichnostnogo i professional'nogo samoopredeleniya starsheklassnikov v protsesse planirovaniya kar'ery. Avtoref. Kand. Diss. [Pedagogical conditions of personal and professional identity of high school students in process of career planning. Cand. Diss. Thesis]. Tomsk, 2000. 18 p.

19. Tokarsky B. L., Tokarskaya N. M. Sociological research of public economic motivation. Izvestiya Irkutskoy gosudarstvennoy ekonomicheskoy akademii = Bulletin of Irkutsk State Economics Academy, 2005, no. 1 (42), pp. 75-81. (In Russian).

20. Kolomeitsev Yu. A., Zhdanovich A. A. Main scientific approaches to professional career and personal career orientation. Problemy upravleniya = Problems of Management, 2008, no. 1 (26), pp. 207-215. (In Russian).

21. Ozernikova T. G. Motivation and competitive ability of workers: problems of interconnection. Izvestiya Irkutskoy gosudarstvennoy ekonomicheskoy akademii = Bulletin of Irkutsk State Economics Academy, 2005, no. 1 (42), pp. 71-75. (In Russian).

22. Samarukha V. I., Gulyaeva A. V. Role of social sphere in improving public quality of living. Izvestiya Irkutskoy gosudarstvennoy ekonomicheskoy akademii = Bulletin of Irkutsk State Economics Academy, 2011, no. 4 (78), pp. 46-50. (In Russian).

\section{Информация об авторе}

Агафонова Валерия Павловна - аспирант, кафедра политологии и социологии, Бурятский государственный университет, 670000, г. Улан-Удэ, ул. Смолина, 24 а; ассистент, кафедра правового обеспечения и национальной безопасности, Байкальский государственный университет, 664003, г. Иркутск, ул. Ленина, 11, e-mail: panorama_17@mail.ru.

\section{Author}

Valeria P. Agafonova - PhD Student, Chair of Political Science and Sociology, Buryat State University, 24a Smolin St., 67000, Ulan-Ude, Russian Federation; Assistant Lecturer, Chair of Legal Support and National Security, Baikal State University, 11 Lenin St., 664003, Irkutsk, Russian Federation; e-mail: panorama_17@mail.ru.

\section{Библиографическое описание статьи}

Агафонова В. П. Подходы к пониманию карьеры, ее сущность и особенности / В. П. Агафонова // Baikal Research Journal. - 2016. - T. 7, № 3. - DOI : 10.17150/2411$\underline{6262.2016 .7(3) .21}$.

\section{Reference to article}

Agafonova V. P. Approaches to understanding career, its essence and features. Baikal Research Journal, 2016, vol. 7, no. 3. DOI : 10.17150/2411-6262.2016.7(3).21. (In Russian).

\section{Baikal Research Journal}

